\title{
Effects of Nopal Mucilage (Opuntia ficus-indica) as Plasticizer in the Fabrication of Laminated and Tubular Films of Extruded Acetylated Starches
}

\author{
Caroline Andreuccetti, ${ }^{1}$ Tomás Galicia-García $\mathbb{D}^{2},{ }^{2}$ Fernando Martínez-Bustos, ${ }^{3}$ \\ Raimundo Ferreira Grosso, ${ }^{4}$ and Rubén González-Núñez $\varpi^{5}$ \\ ${ }^{1}$ Faculty of Animal Science and Food Engineering, FZEA, University of São Paulo, USP, 13635-900 Pirassununga, SP, Brazil \\ ${ }^{2}$ Facultad de Ciencias Químicas, Universidad Autónoma de Chihuahua, Circuito Universitario, Campus Universitario \#2, CP, \\ 31125 Chihuahua, Chihuahua, Mexico \\ ${ }^{3}$ CINVESTAV-Unidad Querétaro, Libramiento Norponiente 2000, Fracc, Real Juriquilla, Qro, 76001 Querétaro, Mexico \\ ${ }^{4}$ Department of Foods and Nutrition, Faculty of Food Engineering, University of Campinas, UNICAMP, 13083-862 Campinas, \\ SP, Brazil \\ ${ }^{5}$ Departamento de Ingeniería Química, Universidad de Guadalajara, Blvd. Marcelino García Barragán No. 1451, CP, \\ 44430 Guadalajara, Jalisco, Mexico
}

Correspondence should be addressed to Tomás Galicia-García; tgalicia@uach.mx

Received 11 November 2020; Revised 15 April 2021; Accepted 21 April 2021; Published 30 April 2021

Academic Editor: Marta Fernández García

Copyright (C) 2021 Caroline Andreuccetti et al. This is an open access article distributed under the Creative Commons Attribution License, which permits unrestricted use, distribution, and reproduction in any medium, provided the original work is properly cited.

\begin{abstract}
Normal and acetylated rice and waxy maize starches with a blend of nopal mucilage (Opuntia ficus-indica) and glycerol were used for the preparation of laminated and tubular films by extrusion and blown extrusion, respectively. The composition of the formulation was $70 \%$ starch (normal or acetylated), $20 \%$ glycerol, and $10 \%$ nopal mucilage $(w / w)$. The degrees of substitution (DS) for acetylated rice starch (0.94) and waxy maize starch (0.76) present high potential for use as a polymeric matrix in packing materials. The use of nopal mucilage can improve the processability of extruded and tubular films by favoring the increase of some mechanical and functional properties. The films elaborated with nopal mucilage and glycerol present a homogeneous relief without breaking, adhesiveness, and contraction once formed. The elongation values of acetylated waxy maize starch films (33\%) were higher than those of rice acetylated films (17\%), while the blown films presented a $30 \%$ decrease in tensile strength, compared to the laminated films. Acetylation generated more hydrophobic material for the rice starch sample, which can be evidenced by a decreased solubility of the laminated films. Films of both sources of acetylated starch showed a significant decrease in water vapor permeability and showed a plasticized starch disposition-type layer without unmelted starch granules.
\end{abstract}

\section{Introduction}

The thermoplastic processing of starch has a wide application for its specified functional properties. Heating amorphous thermoplastic agro-polymers as starch above the glass transition temperature produces soft and rubbery materials and may allow their incorporation into specific products such as packaging materials. Cooling to room temperature can reconvert rubbery products to glassy materials, giving more or less rigid forms with the desired structure [1]. The application of different thermoplastification processes used in manufacturing synthetic polymers has been applied to the fabrication of biodegradable polymers. These processes include injection molding, extrusion blow molding, injection compression molding, and extrusion [2]. Plasticizers, such as glycerol, sorbitol, glycols, maltodextrin, urea, and surfactants, are often used to improve the mechanical properties of the film, increasing film flexibility and allowing a significant change in their barrier properties $[3,4]$. Additionally, the starch network can be easily deformed without rupture with the use of plasticizers, because plasticizer molecules are smaller and more mobile than the starch molecules [5]. Recently, much attention has been paid to the 
preparation of fully biodegradable composites with starch and their derivatives $[5,6]$. Modifications in the structure of starch by placing substituents along its polymeric backbone are usually made to increase the performance of native starch. Acetylation, hydroxypropylation, and crosslinking are widely used methods to prepare modified starches associated with the thermoplasticization process, improving the mechanical behavior of the obtained biodegradable materials [7-10]. Acetylated corn starch films by casting were obtained with good water vapor barrier properties and adequate mechanical features [11]. Recently, films fabricated by extrusion with waxy maize starch, glycerol, and cactus mucilage (Opuntia ficus-indica) showed good mechanical properties and low water vapor permeability and water solubility values [12]. Also, the films were homogeneous with uneven surfaces and little roughness.

Films prepared by calendaring or extrusion blowing processes with acetylated starch or mixtures of native and acetylated starches with gelatin, glycerol, or other plasticizers or surfactants resulted in materials with desirable functional and mechanical characteristics indicating that they are a good option as a food packaging materials [10-19].

Nopal (Opuntia ficus-indica) is a native cactaceae to desert regions of Mexico [20]. An aqueous solution of mucilage has a non-Newtonian rheological to pseudoplastic behavior. These solutions have a great elasticity, similar to that of synthetic polymer such as polyisobutylene. Concentrations of $10 \%$ improved the rheological behavior of the mucilage, and it is similar to an aqueous solution of $3 \%$ of xanthan gum [21]. Thus, nopal mucilage can act as a plasticizer improving mechanical properties of plasticized starch [12]. The aim of this research was to evaluate the effects of nopal mucilage (Opuntia ficus-indica) as a plasticizer in the fabrication of laminated by thermoplastic extrusion and tubular films by blown extrusion of acetylated starches from waxy maize and rice starches.

\section{Materials and Methods}

2.1. Material. Rice and waxy maize starches were purchased from Corn Products (Mexico). Glycerol (JT Baker, NJ, USA) and mucilage of Opuntia ficus-indica were used as plasticizers. The mucilage was extracted according to the methodology of Morín [12].

\subsection{Methods}

2.2.1. Starch Acetylation by Extrusion. Starch acetylation was performed by using the thermoplastic extrusion process [22], using acetic anhydride as an esterifying agent. The moisture content of native starch was adjusted to $22 \%$, with further addition of $5.5 \mathrm{~g}$ of acetic anhydride, and then, the sample was stored for $12 \mathrm{~h}$. Afterwards, $50 \mathrm{~mL}$ of sodium hydroxide (10\%) was added and the $\mathrm{pH}$ was adjusted at 8.5-9; furthermore, the suspension was homogenized and processed in a laboratory single-screw extruder (Cinvestav-Queretaro) with an $\mathrm{L} / \mathrm{D}$ ratio $19 / 25 \mathrm{D}$ with a screw compression ratio of $2: 1$ and circular die with a diameter of $2.8 \mathrm{~mm}$. The barrel temperature profiles used were 60,80 , and $100^{\circ} \mathrm{C}$ in feeding, transition, and high-pressure zones, respectively. The feed rate and screw velocity were constant (18 and $50 \mathrm{rpm}$, respectively). The material was cut in a dimension of $1 \mathrm{~cm}$ and dried in an oven with air circulation at $50^{\circ} \mathrm{C}$ (moisture content of $11 \%)$. Finally, the acetylated starch was milled in a knife mill (Braun, Mexico) and sieved through a 60 mesh $(250 \mu \mathrm{m})$. By means of this technology, the effect of mechanical shear, effect of compression of the screw, and thermal effects were combined, where the incorporation of the acetate group was favored by availability of glucose molecules [22].

2.2.2. Percentage of Acetylation and Degree of Substitution. The percentage of acetylation and degree of substitution were calculated according to the methodology of Sodhi and Singh [23].

2.2.3. Preparation of Laminated Films. Film formulations were selected from the previous work [12] where were reported the following: (1) with plasticizer-70\% starch (native or acetylated), 20\% glycerol, and 10\% mucilage of Opuntia ficus-indica and (2) without plasticizer-70\% starch (native or acetylated) and 30\% mucilage of Opuntia ficusindica; these ingredients were constantly mixed to obtain a homogeneous mass, without lumps. The treatments, based on native and acetylated starch, were adjusted to $18 \%$ of moisture and mixed with ingredients in a proportion based on the formulation selected. Every sample was processed in a laboratory single-screw extruder (Cinvestav, Qro., Mexico), with a L/D ratio of $19 / 25$, a screw compression ratio of $1: 1$, and $40 \mathrm{~mm} \times 0.5 \mathrm{~mm}$ rectangular die. The profile barrel temperatures were feeding zone $50^{\circ} \mathrm{C}$, transition zone $65^{\circ} \mathrm{C}$, and compression zone $60^{\circ} \mathrm{C}$.

The three zones were electrically heated and air cooled independently. The feed screw was constant at $18 \mathrm{rpm}$, and the screw speed was $36 \mathrm{~Hz}(49.98 \mathrm{rpm})$. The heating zones in the extruder barrel were controlled using thermocouples and the laminated films by the thermoplastic extrusion process.

2.2.4. Preparation of Tubular Films. The formulation used was $70 \%$ acetylated starch (rice or waxy maize, $20 \%$ glycerol, and $10 \%$ mucilage of Opuntia ficus-indica). Before the manufacture of tubular films by blown extrusion, the sample was pelletized using a laboratory single-screw extruder (Cinvestav, Qro., Mexico), with a L/D ratio of $20: 1$, screw compression ratio of $1: 1$, and a circular die with a diameter of $3 \mathrm{~mm}$. The barrel temperatures were 30, 40, and $50^{\circ} \mathrm{C}$, in the feeding, transition, and compression zones, respectively. The feed screw and screw speed were kept constant (18 rpm and $42 \mathrm{~Hz}$, respectively). The pellets were stored at $5 \pm 2{ }^{\circ} \mathrm{C}$ and $60 \pm 2 \%$ relative humidity.

The tubular films were obtained in a single-screw extruder (Haake Model Rheomex 254, Germany) coupled with a blown film device. The technical specifications of the experimental setup were as follows: a screw diameter (D) of $19 \mathrm{~mm}$, a screw length of $25 \mathrm{D}$, three heating zones (feeding $45^{\circ} \mathrm{C}$, transition $60^{\circ} \mathrm{C}$, and compression $80^{\circ} \mathrm{C}$ ), an annular die with a diameter of $25 \mathrm{~mm}$, a pin diameter of $24 \mathrm{~mm}$ and a gap width of $0-0.8 \mathrm{~mm}$, and a heater capacity/zone of $1000 \mathrm{~W}$. A screw speed of $40 \mathrm{rpm}$ and die temperature of 
$110^{\circ} \mathrm{C}$ were used. Die diameter, bubble diameter, die thickness, and bubble thickness are used in equation (1). The thickness relation (TR), blow-up ratio (BUR) (which indicates the amount of stretching in the hoop direction of the bubble), take-up ratio (TUR) (which indicates the amount of stretching along the long axis of the bubble), and formation radius (FR) (which indicates the balance of stretching and, thus, the orientation between the machine and transverse direction) were calculated according to the following equations as defined by Cantor [24]:

$$
\begin{aligned}
\mathrm{TR} & =\frac{\text { die thickness }}{\text { bubble thickness }}, \\
\mathrm{BUR} & =\frac{\text { bubble diameter }}{\text { die diameter }}, \\
\mathrm{TUR} & =\frac{(\rho \mathrm{A})_{\text {die }} \text { gap }}{(\rho \mathrm{A})_{\text {niprollers }}},
\end{aligned}
$$

where $\rho$ is the density,

$$
A(\text { annular area })=A=\pi\left(R_{\mathrm{o}}^{2}-R_{\mathrm{i}}^{2}\right),
$$

where $R_{\mathrm{o}}$ is the outer radius and $R_{\mathrm{i}}$ is the inner radius of the annulus.

$$
\mathrm{FR}=\frac{\mathrm{TUR}}{\mathrm{BUR}}
$$

The purpose of this process was to generate a bidirectionality in the polymer chains favoring the mechanical and functional properties of the blown films obtained.

2.3. Functional Properties. Before characterization, the films were stored in desiccators $\left(25 \pm 2^{\circ} \mathrm{C}, 50 \pm 2 \% \mathrm{RH}\right.$, and $\mathrm{Mg}$ $\left.\left(\mathrm{NO}_{3}\right)_{2} \cdot 6 \mathrm{H}_{2} \mathrm{O}\right)$ for 3 days.

2.3.1. Thickness and Visual Aspect. The thickness of the films was determined using a Mitutoyo Corp. digital micrometer (Tokyo, Japan) analyzing an average of seven random measurements. Both visual and tactile analyses were conducted for all the films obtained with the aim of using only homogeneous films with uniform color and without any phase separation, exudation, insoluble particles, and brittle zones.

2.3.2. Mechanical Properties. The mechanical properties (tensile strength and elongation) were determined according the ASTM D882-10 method [25], using a texturometer TA.XT2 (Stable Micro Systems, Surrey, UK). All assays were performed in triplicate.

2.3.3. Water Solubility. The solubility of the films $(2 \mathrm{~cm}$ diameter discs) was determined according to the method described by [26] after $24 \mathrm{~h}$ of immersion in distilled water $(50 \mathrm{~mL})$ with mechanical stirring at room temperature $\left(25 \pm 2^{\circ} \mathrm{C}\right)$. The samples were then removed from the solution and dried in a forced air oven $\left(105^{\circ} \mathrm{C}\right.$ for $\left.24 \mathrm{~h}\right)$. The initial dry mass was determined from the sample moisture content. These determinations were performed in triplicate.
2.3.4. Water Vapor Permeability. The water vapor permeability (WVP) $\left(\mathrm{g} \cdot \mathrm{mm} \cdot \mathrm{m}^{-2} \cdot \mathrm{h}^{-1} \cdot \mathrm{kPa}^{-1}\right)$ at $25 \pm 2^{\circ} \mathrm{C}$ was determined using the ASTM E96-95 method [27]. The cells were filled with anhydrous calcium chloride $(0 \% \mathrm{RH})$, covered with the conditioned films, sealed, and placed in desiccators containing a saturated $\mathrm{NaCl}$ solution $(75 \pm 3 \% \mathrm{RH})$. The samples were weighed in triplicate five times each over a $48 \mathrm{~h}$ period, and the data were recorded in a graph of weight gain vs. time.

2.3.5. Morphology of the Films. The films were fractured with liquid nitrogen and then mounted on aluminum stubs in longitudinal and transverse position, for morphological observations of the surface and cross-section of the films using a scanning electron microscope Philips ${ }^{\circledR}$ (XL30 ESEM, Eindhoven, Netherlands) at an accelerating voltage of $15 \mathrm{kVA}$.

2.4. Statistical Analyses. The statistical analyses were carried out using SAS for Windows version 8.0 (Cary, North Carolina, USA, 2012), and the differences between the means were determined by the Tukey multiple test $(p \leq 0.05)$.

\section{Results and Discussion}

3.1. Percentage of Acetylation and Degree of Substitution. The percentages of acetylation and the degree of substitution (DS) varied according to the type of starch. The percentage obtained for rice starch was $24.85 \% \pm 0.78$ and DS of 0.94 \pm 0.03 , followed by waxy maize starch that had $20.06 \% \pm$ 1.82 and DS of $0.76 \pm 0.07$, respectively. The difference in DS values is mainly due to the botanical source where the rice starch reported an amylose concentration (19\%) and granular size $(2-8 \mu \mathrm{m})$ different from those observed in waxy corn maize ( $<10 \%$ amylose and $10-30 \mu \mathrm{m}$ in granular size) [28, 29]. A starch with high amylose concentration and granules with high size presented a low-grade modification [30, 31]. The crosslinking that occurs by the introduction of acetyl groups changes the absorption of water in the material, which modified the shear effect that occurs during extrusion, this effect being more pronounced depending on the conditions of the process used [22]. Previous studies [32] reported a degree of substitution of 1.12 in waxy corn starch using $2.25 \mathrm{~g}$ acetic acid/100 g starch anhydride, while [33] reported values of 0.033 , using the same concentrations and technique presenting an additional step during the extrusion process to finish the acetylation. Low degrees of substitutions in starch are recommended for food use.

The FDA allowed a maximum DS of 0.2 for acetylated starches [34]. Therefore, the degree of acetylation of the modified starches does not allow the use of them as food grade; however, this does not restrict its use in packaging materials.

\subsection{Characterization of Laminated and Tubular Films Based on Acetylated and Normal Starches with Nopal Mucilage and Glycerol}

3.2.1. Visual Aspect and Thickness. Laminated films of rice, waxy maize, and acetylated starches processed by thermoplastic extrusion presented good conditions of processability, homogeneous surface, and maintained flexibility after 
storage. These characteristics can be due to the partial destruction of the structure of starch during the extrusion process becoming less susceptible to acetylation [22] and the interaction of mucilage and glycerol as plasticizer [12]. For acetylated waxy maize films, the thicknesses values $(0.46 \pm 0.06 \mathrm{~mm})$ showed an increase of $26 \%$ with respect to the native starch film $(0.34 \pm 0.06 \mathrm{~mm})$, while the value for starch-based films of native rice $(0.47 \pm 0.06 \mathrm{~mm})$ decreased by $8 \%$ compared to the modified rice starch film $(0.50 \pm 0.01 \mathrm{~mm})$. These values were lower than those reported in blue corn films, using sorbitol and glycerol (30 and $40 \%$ ) as plasticizers [35], as well as the values reported in yam starch films [36] using a starch: glycerol ratio $(4: 1.3$, respectively). The difference was due to the high absorption of water in acetylated starch and the interaction with mucilage-glycerol, as plasticizers [18].

Using the casting method, it was reported that the thickness of the films with blends of native and acetylated corn starches and with glycerol exhibited a multilayer structure and was significantly affected by the composition. The higher acetylation of the starch concentration, the higher the film thickness attributed to the incorporation of acetyl groups which interfere with the alignment of the chains due to steric hindrance [11].

Only acetylated starches (rice and waxy maize) afforded the fabrication of tubular films, as shown in Figures 1(a) and $1(\mathrm{~b})$, respectively. Both presented low differences in appearance mainly due to their source characteristics [37] such as the size of the granule and the DS present in the source [29]; nevertheless, the films had a uniform relief without cracks, adhesiveness, and shrinkage once formed, thus such as the null presence of nonplasticized material, these being indicative that the samples obtained showed a homogeneous matrix that does not represent damage of the mechanical properties evaluated $[15,22]$.

In turn, the unmodified starches, regardless of the source, exhibited limitations in processing by blown extrusion, the material did not show sufficient extensibility, the diameter of the tubular film was inadequate (low formation radius), and the material blown extruded showed instability problems after bubble formation. The acetylation process, therefore, contributed to the improvement of the processability conditions and the formation of tubular films, expanding the possibilities of use of this type of material in the biopolymer industry.

The parameters determined and calculated during the processing of acetylated rice and waxy maize starch films by blown extrusion are shown in Table 1. The thicknesses relation indicated that the output thickness decreased 5.79 times (950 to $160 \mu \mathrm{m})$ and $6.56(636$ to $97 \mu \mathrm{m})$ times for acetylated rice and acetylated waxy maize starches, respectively, in comparison with the initial thickness film (die thickness), these values being lower than those reported in literature [15] in blown films based on gelatin and yucca extract $(357 \mu \mathrm{m}$ and $166 \mu \mathrm{m}$ and a plasticizer concentration of 0.25 and $8.75 \%$, respectively) that when they increased, a low thick film was generated. Rodríguez-Castellanos et al. [16] reported thickness in a sorghum starch film with yucca extract varying from $200-350 \mu \mathrm{m}$, at $20 \%$ of plasticizer, according the parameters used during the extrusion process (screw speed and temperature), which indicates that the nopal mucilage presented a synergic effect with plasticizer that favored the reduction of initial thickness by the blowing process.

The blown relation was increased 1.4 times in acetylated rice and waxy maize starch films, which indicates that the samples presented a low orientation in flow direction during the process, as it was shown in formation ratio (FR) values. The extrusion processing parameters were adjusted at $105^{\circ} \mathrm{C}$ barrel temperature and $25 \mathrm{rpm}$ screw speed. Some researchers had reported certain stickiness of thermoplastic starch (TPS) films fabricated by the blowing process when they emerged from the die $[13,18]$. These authors stated that the starch humidity susceptibility and the migration of the plasticizer to the surface of the film caused bubble blown failures, as well as problems related with the film stickiness. Buehler et al. [38] proposed the use of other plasticizers, such as sorbitol and urea, as a supplement or replacement of glycerol, as considered in this work with the use of nopal mucilage.

Andreuccetti et al. [15] reported the final thickness obtained through three processing techniques (casting, thermoplastic, and blown extrusion) using a plasticizer concentration of $8.73 \%$, presenting a lower thickness (60\%) for the casting technique in contrast to that obtained by the blowing process, and 33\% higher in thermoplastic extrusion; while the plasticizer concentration of $0.25 \%$ doubled the thickness of the film obtained by the blown extrusion process.

3.2.2. Mechanical Properties. For laminated film samples, both the tensile strength and the elongation of films were influenced by the chemical modification of starch and by plasticizer addition (glycerol and nopal mucilage) (Table 2).

Acetylated laminated films showed a reduction (approximately $17.5 \%$ for rice starch and $26 \%$ for waxy maize starch) in elongation compared to rice and maize starches. For materials without plasticizer, the elongation values of acetylated waxy maize starch films (32.68\%) were higher than those of rice acetylated films (17.03\%) (Table 2). These values are close to those reported in the literature [18] to values of $\varepsilon$ (20.14\%), in films based on $75 \%$ of acetylated starch, $5 \%$ native starch, and $20 \%$ of glycerol.

The tensile strength $(\sigma)$ of acetylated starches (rice and waxy maize) resulted in films of higher resistance than the films of their native starches, for films with or without plasticizer. This behavior suggests that the chemical modification reduces the secondary interactions between starch chains due to the substitution of the hydroxyl groups by acetate groups [39]. Some authors have reported that the acetylation of starch increases the flexibility of the films [40] due to steric interference with an intermolecular alignment of amylose and segments of amylopectin branches by the extrusion process [22], as well as a reduction of intermolecular interaction and cohesion between starch and plasticizer where intermolecular interactions are present and increase the volumes in polymeric chains, so that this behavior can be different in unmodified starch films due to the extrusion process where the shear is more effective on untreated starch compared to the modified starch film [41]. 


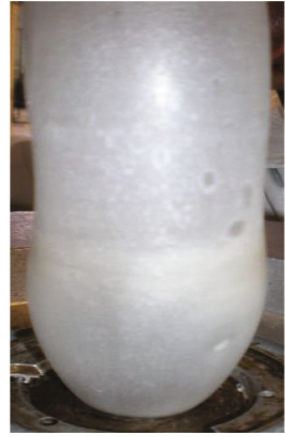

(a)

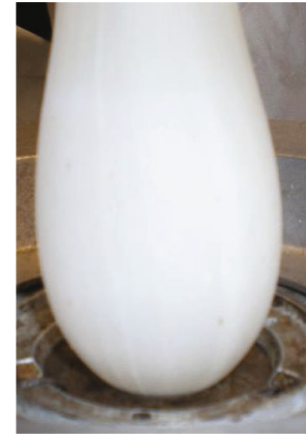

(b)
Figure 1: Tubular films based on acetylated waxy maize (a) and acetylated rice (b) starches fabricated by the blown extrusion process.

TABle 1: Processing parameters of acetylated rice and waxy maize starch films with mucilage and glycerol as plasticizer, during the blown extrusion process.

\begin{tabular}{lccc}
\hline Parameters processing & Units & Rice & Waxy maize \\
\hline Speed screw (Vt) & $\mathrm{rpm}$ & 25 & 25 \\
Die ratio (Ro) & $\mathrm{mm}$ & 12.15 & 12.15 \\
Initial ratio of film (Ri) & $\mathrm{mm}$ & 7.50 & 9.00 \\
Final ratio of film (Rf) & $\mathrm{mm}$ & 10.50 & 13.00 \\
Initial thicknesses film (Ho) & $\mathrm{mm}$ & 0.927 & 0.636 \\
Final thicknesses film (Hf) & $\mathrm{mm}$ & 0.160 & 0.097 \\
Thicknesses relation (TR) & & 5.79 & 6.56 \\
Blown relation (BUR)* & & 1.40 & 1.44 \\
Formation ratio (FR)* & & 0.12 & 0.14 \\
Die temperature (Td) & ${ }^{\circ} \mathrm{C}$ & 105 & 105 \\
\hline
\end{tabular}

${ }^{*}$ Dimensionless parameters.

In tubular film samples, nopal mucilage acted as a plasticizer in combination with glycerol when included in starchbased formulations, once its molecule occupies a small space (low molecular weight, $92.09 \cdot \mathrm{g} \cdot \mathrm{mol}^{-1}$ ), and can be introduced between the branches of mucilage molecules [3] of high molecular weight $\left(13 \times 10^{6} \cdot \mathrm{g} \cdot \mathrm{mol}^{-1}\right)[42]$. Both types of used processes (thermoplastic and blown extrusion) had an influence on the mechanical properties (tensile strength and elongation at break) in acetylated starch films. In film-based acetylated rice starch films, the blowing process produced low-strength films, with a decrease of approximately $30 \%$ in tensile strength relative to films obtained by the thermoplastic extrusion process. Waxy maize starch films processed by blown extrusion presented an opposite behavior; high values of tensile strength were observed $(3.48 \mathrm{MPa})$ compared to the film produced by thermoplastic extrusion. These values were reported by Zullo and Iannace [43] in corn starch films obtained by blown extrusion using $30 \%$ of a plasticizer concentration; however, a low report [18] in acetylated starch films with $20 \%$ glycerol obtained by the blown extrusion process, where the incorporation of acetylated starches with a low degree of substitution $(0.5-0.8 \%)$ represented a reinforcement in polymeric matrix, favored the $\varepsilon$ values. The elonga- tion at break showed a decrease in both starch types processed by blown extrusion, compared to the films fabricated by the thermoplastic extrusion process. Once the molecular gaps have been covered, the distances between mucilage molecules will increase and a mucilage solution diluted in glycerol can be achieved, thus providing flexibility to the polymer [44].

This behavior is highly related to that reported [45] where a film with low elongation values showed high tensile strength values, mainly to molecular directionality the polymer chains where the crystallinity phase showed a uniaxial direction relative to the plane of equilibrium of starch during the thermoplastic extrusion process, unlike the blown extrusion process where high interaction points were present, as well as a crosslinking product to molecular bidirectionally [46].

3.2.3. Solubility. Waxy maize and rice starches naturally have a hydrophilic character, and when they are subjected to a thermomechanical process during extrusion, the branched chains of the starch open and allow the entry of water as well as the incorporation of glycerol and mucilage reaching lamination and plasticization. The thermoplastic extrusion process resulted in compact films (Figure 2); the solubility values of the film were not so high, with lower values than $21 \%$ (Table 2). The modification of starch by acetylation showed different values according to the type of starch. Acetylation generated more hydrophobic material for the rice starch, which can be evidenced by a lower solubility of the laminated films, while the films produced with waxy maize starch (native or modified) were more soluble in water, with a minimum of $18.42 \%$ solubility for native rice starch. The chemical modification incorporated acetyl groups which reduce the interaction between the starch molecules, consequently increasing the solubility and swelling power of the starch granule. This change is caused by steric effects and destabilization of hydrogen bonds generating an intragranular disintegration, which will facilitate the access of water to the amorphous areas [7, 47].

Tubular films fabricated by the blown extrusion process presented more solubility, regardless of the type of starch tested. The processing of tubular films could have caused a drastic modification in the structure of the film during its formation due to the stretching of the polymer chains, and more molecules would open allowing more interaction with water molecules and, consequently, causing a greater disruption of the film due to its increased solubility [18].

3.2.4. Water Vapor Permeability (WVP). Regardless the type of starch, the acetylation modification resulted in a significant decrease in water vapor permeability (WVP) compared to unmodified film-based starches (Table 2). For rice starch, a decrease of approximately 56\% (without plasticizer) and 38\% (with plasticizer) was observed, in WVP, while for waxy maize starch, a reduction of $92 \%$ and $38 \%$ was observed for materials without and with plasticizer, respectively.

The WVP values, for the films prepared with rice starch, unmodified or acetylated without plasticizer, generated less permeable materials, with values between 0.21 and 
TABLE 2: Functional properties of laminated and blown films based on native and acetylated rice and waxy maize starches.

\begin{tabular}{|c|c|c|c|c|c|c|}
\hline Type of starch & Process & Plasticizer & $\begin{array}{l}\text { Tensile strength } \\
\text { (MPa) }\end{array}$ & $\begin{array}{l}\text { Elongation } \\
(\%)\end{array}$ & $\begin{array}{c}\text { Water solubility } \\
(\%)\end{array}$ & $\begin{array}{l}\text { Water vapor permeability } \\
\quad\left(\mathrm{g} \cdot \mathrm{mm} \cdot \mathrm{m}^{-2} \cdot \mathrm{h}^{-1} \cdot \mathrm{kPa}^{-1}\right)\end{array}$ \\
\hline \multirow{2}{*}{ Native } & \multirow{2}{*}{ Extrusion } & Without & $2.80 \pm 0.33^{\mathrm{b} *}$ & $20.30 \pm 0.70^{c}$ & $20.91 \pm 1.02^{\mathrm{a}}$ & $0.48 \pm 0.03^{b}$ \\
\hline & & With & $3.30 \pm 0.21$ & $20.63 \pm 2.8$ & $19.00 \pm 0.14$ & $2.43 \pm 0.67$ \\
\hline \multirow{3}{*}{ Acetylated } & \multirow{2}{*}{ Extrusion } & Without & $3.96 \pm 0.17^{\mathrm{a}}$ & $17.03 \pm 1.59^{c}$ & $19.47 \pm 0.62^{\mathrm{a}}$ & $0.21 \pm 0.03^{c}$ \\
\hline & & With & $3.90 \pm 0.20$ & $18.5 \pm 1.03$ & $18.42 \pm 0.79$ & $1.51 \pm 0.02$ \\
\hline & Blowing & With & $2.82 \pm 0.47$ & $12.07 \pm 1.78$ & $22.59 \pm 0.97$ & $3.10 \pm 0.05$ \\
\hline \multirow{2}{*}{ Native } & \multirow{2}{*}{ Extrusion } & Without & $0.11 \pm 0.03$ & $20.63 \pm 2.80^{\mathrm{a}}$ & $15.61 \pm 0.65^{b}$ & $2.13 \pm 0.07^{\mathrm{a}}$ \\
\hline & & With & $1.20 \pm 0.10^{\mathrm{d}}$ & $46.46 \pm 3.62$ & $21.00 \pm 0.05$ & $3.82 \pm 0.03$ \\
\hline \multirow{3}{*}{ Acetylated } & \multirow{2}{*}{ Extrusion } & Without & $1.06 \pm 0.25^{c}$ & $32.68 \pm 3.40^{\mathrm{b}}$ & $19.78 \pm 1.70$ & $0.16 \pm 0.03^{c}$ \\
\hline & & With & $3.3 \pm 0.03$ & $34.40 \pm 0.80$ & $20.19 \pm 0.09$ & $2.35 \pm 0.04$ \\
\hline & Blowing & With & $3.48 \pm 0.64$ & $11.19 \pm 1.55$ & $25.65 \pm 0.10$ & $0.82 \pm 0.02$ \\
\hline
\end{tabular}

${ }^{*}$ Average \pm standard deviation. Different letters on the same column represent significant differences $(p \leq 0.05)$ between the averages obtained in the Tukey test.

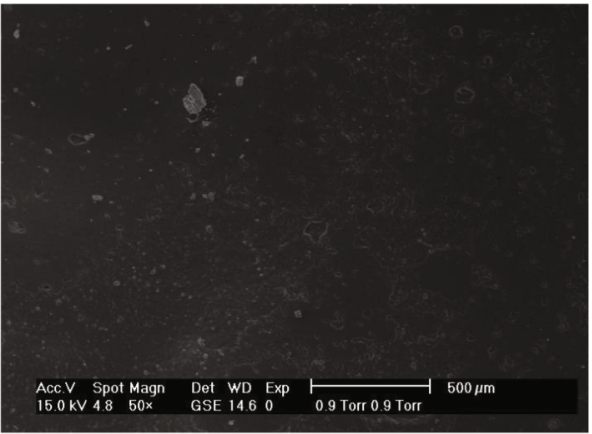

(a)

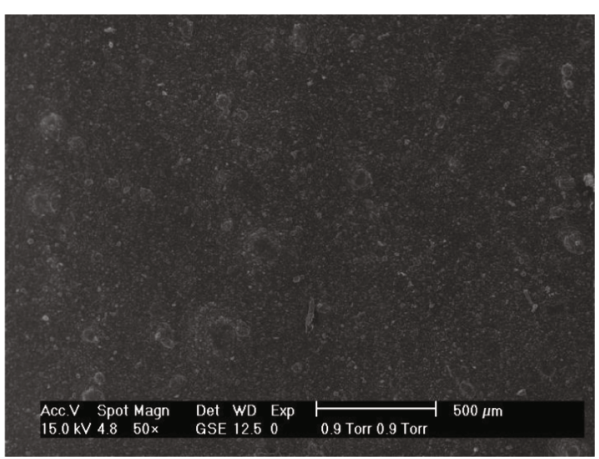

(c)

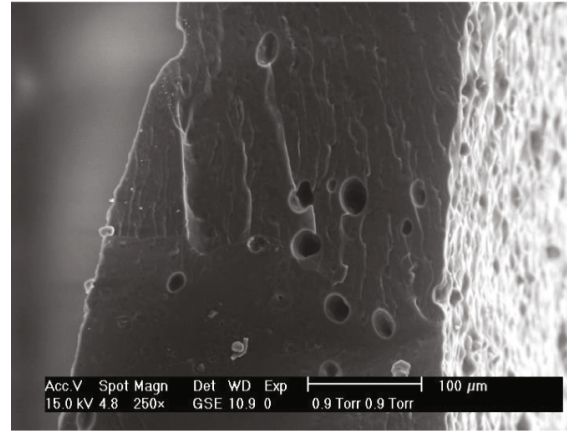

(b)

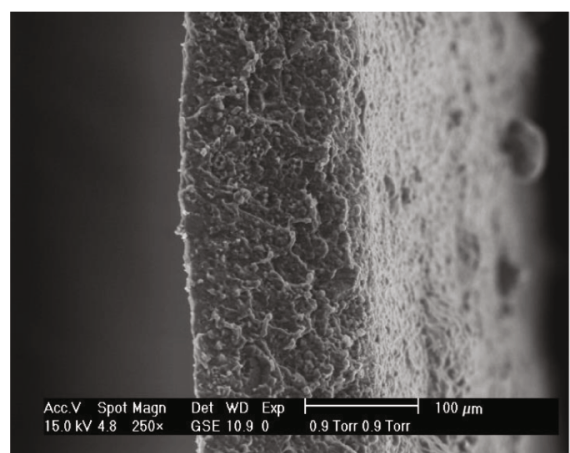

(d)

FIGURE 2: SEM micrographs of the surface (left column, 50x) and internal structure (right column, 250x) of films based on acetylated waxy maize $(a, b)$ and rice $(c, d)$ starches plasticized with glycerol and nopal mucilage obtained by blown extrusion processes.

$0.48 \mathrm{~g} \cdot \mathrm{mm} \cdot \mathrm{m}^{-2} \cdot \mathrm{h}^{-1} \cdot \mathrm{kPa}^{-1}$, respectively, unlike samples with plasticizer $\left(1.5\right.$ to $\left.2.5 \mathrm{~g} \cdot \mathrm{mm} \cdot \mathrm{m}^{-2} \cdot \mathrm{h}^{-1} \cdot \mathrm{kPa}^{-1}\right)($ Table 2$)$, due to the presence of hydrophilic additives (glycerol and mucilage) in formulation. This behavior was similar to that reported in acetylated films based on maize starch where values were presented in a range of 0.76 to $0.88 \mathrm{~g} \cdot \mathrm{mm} \cdot \mathrm{m}^{-2} \cdot \mathrm{h}^{-1} \cdot \mathrm{kPa}^{-1}$ and 0.81 to $0.92 \mathrm{~g} \cdot \mathrm{mm} \cdot \mathrm{m}^{-2} \cdot \mathrm{h}^{-1} \cdot \mathrm{kPa}^{-1}$ for the untreated films, due to the extrusion process which may have resulted in a certain degree of depolymerization and the breaking of hydrogen bonds in the starch, which in turn facilitated absorption of water [41].
Glycerol, due to its size, easily penetrates the film structure, and the presence of a hydroxyl group at each carbon forms hydrophilic compositions, resulting in materials with higher WVP [48]. Both types of starch showed a different behavior with respect to WVP when comparing the films obtained by thermoplastic extrusion or blown extrusion. The tubular films produced with acetylated rice starch had a higher WVP, around twice more than the value displayed by the laminate film. The acetylated waxy maize film obtained by the blowing process presented a decrease in 
WVP of approximately $60 \%$ compared to the laminated film; this behavior can be due to the thickness where the blowing effect is arranged with a large distance between polymeric chains favoring the values of increased permeability of the films [15] and the low hydrophobic character product of acetylation by the extrusion process [18].

The acetylated waxy maize starch exhibited $2.25 \mathrm{~g} \cdot \mathrm{mm} \cdot \mathrm{m}^{-2} \cdot \mathrm{h}^{-1} \cdot \mathrm{kPa}^{-1}$ (Table 2), and the effect of glycerol as plasticizer on properties of the film depends on its concentration, being $1.5 \% w / w$ those that allow to obtain the lowest value of WVP $\left(0.06 \mathrm{~g} \cdot \mathrm{mm} \cdot \mathrm{m}^{-2} \cdot \mathrm{h}^{-1} \cdot \mathrm{kPa}^{-1}\right)$, low film solubility in water and a more compact structure than those of nonplasticized films [49].

The films maintain a substantial amount of water within the starch-plasticizer network, resulting in higher WVP values compared to low-density polyethylene (LPDE) that presents WVP of $0.0013 \mathrm{~g} \cdot \mathrm{mm} \cdot \mathrm{m}^{-2} \cdot \mathrm{h}^{-1} \cdot \mathrm{kPa}^{-1}$ [50]. The absorbed moisture, due to plasticization, had a swelling effect that tended to increase the permeability of the film to water vapor. The swelling also disrupted the structural integrity and barrier properties of the polymer network [51].

3.2.5. Scanning Electron Microscopy (SEM). The morphology of the surface and cross-section of films based on acetylated starches of rice and waxy maize plasticized with glycerol and nopal mucilage by means of blown extrusion process to obtain tubular film are presented at Figure 2. The surface of the films, regardless of the starch source used (Figures 2(a) and $2(\mathrm{c})$ ), was uniform and homogeneous, indicating that the film-making process did not cause structural degradation in the material formed. The acetylated waxy maize starch film (Figure 2(a)) showed a smooth surface without cracks, with the presence of some imperfections (small holes) due to the higher loss of water that evaporated during the production process [15]. The acetylated rice starch film (Figures 2(c) and 2(d)) showed a plasticized starch disposition-type layer, without unmelted starch granules; this behavior can be due to the complete plasticization of the material. Singh and Nath [52] reported that the granular structure of acetylated starch partially changes providing a smooth material, compared to that of native starch where there is a granular dispersion in small pieces; this difference was attributed to the esterification that resulted from the substitution of some hydroxyl groups in modified starch. The films presented certain roughness on surfaces, and their structures resulted to be homogeneous and compact [18]; this compaction is related to the low micropores inside the films produced by the rapid evaporation of water during the extrusion process as well as the directionality of polymeric chains [15].

\section{Conclusions}

The acetylated starches showed high levels of acetylation (25 and $20 \%$ in rice and waxy maize starches, respectively) influencing the functional properties of the resulting films. The acetylation did not cause a significant increase in the flexibility of the films, with values less than $33 \%$ of elongation. The mechanical characteristics of the acetylated films facilitated blown extrusion processing in the formation of tubular films, and it expands the usability of such material as feedstock for industrial biopolymers. The incorporation of nopal mucilage solution in laminated and tubular films represented high compatibility in the polymeric matrix. The films showed low solubility with indexes below $25.6 \%$, and the acetylation procedures made it possible to produce materials less permeable to water vapor. In general, the substitution by acetylation resulted in more hydrophobic materials.

\section{Data Availability}

The research article data used to support the findings of this study are included within the article.

\section{Conflicts of Interest}

The authors have declared no conflict of interest.

\section{Acknowledgments}

We would like to thank to National Council of Science and Technology (CONACyT) and ICyTDF for the financial support for this project. This research was funded by the Scientific and Technological Institute of Mexico City (ICyTDF).

\section{References}

[1] B. Cuq, N. Gontard, and S. Guilbert, "Thermoplastic properties of fish myofibrillar proteins: application to the biopackaging fabrication," Polymer, vol. 38, pp. 4071-4078, 1997.

[2] P. Lescher, K. Jayaraman, and D. Bhattacharyya, "Water-free blending of thermoplastic starch and polyethylene for rotomoulding," Starch/Stärke, vol. 61, no. 1, pp. 43-45, 2009.

[3] M. A. García, M. N. Martino, and N. E. Zaritzky, "Microstructural characterization of plasticized starch-based films," Starch/Stärke, vol. 52, no. 4, pp. 118-124, 2000.

[4] P. Myllärinen, R. Partenen, J. Seppälä, and P. Forsell, "Effect of glycerol on behaviour of amylose and amylopectin films," Carbohydrate Polymers, vol. 50, no. 4, pp. 355-361, 2002.

[5] E. Aguilar-Palazuelos, F. Martínez-Bustos, O. JiménezArévalo, T. Galicia-García, and A. Delgado-Rangel, "Potentiality of some natural fibres and native starch for making biodegradable materials," in Food Engineering Research Developments, Chap 10, T. P. Klening, Ed., pp. 279-294, Nova Science Publishers, New York, NY, USA, 2007.

[6] T. Galicia-García, F. Martínez-Bustos, O. Jiménez-Arévalo, and E. Aguilar-Palazuelos, "Mechanical properties of extruded biodegradable films of native starch and sugar cane fibre," in Food Engineering Research Developments, Chap 9, T. P. Klening, Ed., pp. 263-278, Nova Science Publishers, New York, NY, USA, 2007.

[7] C. S. Raina, S. Singh, A. S. Bawa, and D. S. Saxena, "Some characteristics of acetylated, cross-linked and dual modified Indian rice starches," European Food Research and Technology, vol. 223, no. 4, pp. 561-570, 2006.

[8] D. Lafargue, D. Lourdin, and J. Doublier, "Film-forming properties of a modified starch/ $\kappa$-carrageenan mixture in relation to its rheological behaviour," Carbohydrate Polymers, vol. 70, no. 1, pp. 101-111, 2007.

[9] J. M. Fang, P. A. Fowler, C. Escrig, R. González, J. A. Costa, and L. Chamudis, "Development of biodegradable laminate films 
derived from naturally occurring carbohydrate polymers," Carbohydrate Polymers, vol. 60, no. 1, pp. 39-42, 2005.

[10] M. J. A. Briones, Preparation and Characterization of Biodegradable Films by Blow Extrusion. Tesis de Maestría, Cinvestav Unidad Querétaro, Mexico, 2011.

[11] V. O. López, J. C. Lecot, E. N. Zaritzky, and A. M. García, "Biodegradable packages development from starch based heat sealable films," Journal of Food Engineering, vol. 105, no. 2, pp. 254-263, 2011.

[12] A. C. S. Morín, Preparation and Characterization of Edible Films Based on Waxy Maize Starch and Mucilage Cactus (Opuntia Ficus-Indica) Using Thermoplastic Extrusion Technology. Tesis de Maestría, UAQ Querétaro, México, 2010.

[13] M. Thunwall, V. Kuthanov, A. Boldizar, and M. Rigdahl, "Film blowing of thermoplastic starch," Carbohydrate Polymers, vol. 71, no. 4, pp. 583-590, 2008.

[14] T. Galicia-García, F. Martínez-Bustos, O. A. Jiménez-Arévalo et al., "Thermal and microstructural characterization of biodegradable films prepared by extrusion-calendering process," Carbohydrate Polymers, vol. 83, no. 2, pp. 354-361, 2011.

[15] C. Andreuccetti, R. A. Carvalho, T. Galicia-García, F. Martínez-Bustos, R. González-Nuñez, and C. R. F. Grosso, "Functional properties of gelatin-based films containing Yucca schidigera extract produced via casting, extrusion and blown extrusion processes: a preliminary study," Journal of Food Engineering, vol. 113, no. 1, pp. 33-40, 2012.

[16] W. Rodríguez-Castellanos, F. Martínez-Bustos, O. A. JiménezArévalo, R. González-Núñez, and T. Galicia-García, "Functional properties of extruded and tubular films of sorghum starch-based glycerol and Yucca Schidigera extract," Industrial Crops and Products, vol. 44, pp. 405-412, 2013.

[17] M. Chávez-Gutiérrez, M. C. Nuñez-Santiago, C. A. RomeroBastida, and F. Martínez-Bustos, "Effects of coconut oil concentration as a plasticizer and Yucca schidigera extract as a surfactant in the preparation of extruded corn starch films," Starch/Stärke, vol. 66, no. 11-12, pp. 1079-1088, 2014.

[18] V. O. López, E. N. Zaritzky, M. V. E. Grossmann, and A. M. García, "Acetylated and native corn starch blend films produced by blown extrusion," Journal of Food Engineering, vol. 116, no. 2, pp. 286-297, 2013.

[19] R. Villalobos, P. Hernández-Muñoz, and A. Chiralt, "Effect of surfactants on water sorption and barrier properties of hydroxypropyl methylcellulose films," Food Hydrocolloid, vol. 20, no. 4, pp. 502-509, 2006.

[20] M. Ennouri, H. Fetoui, E. Bourret, N. Zeghal, F. Guernazi, and H. Attia, "Evaluation of some biological parameters of Opuntia ficus indica. 2. Influence of seed supplemented diet on rats," Bioresource Technology, vol. 97, no. 16, pp. 21362140, 2006.

[21] L. Medina-Torres, "Rheological properties of the mucilage gum (Opuntia ficus indica)," Food Hydrocolloid, vol. 14, no. 5, pp. 417-424, 2000.

[22] S. Mali and M. V. E. Grossmann, "Preparation of acetylated distarch adipates by extrusion," Food Science and Technology, vol. 34, no. 6, pp. 384-389, 2001.

[23] N. S. Sodhi and N. Singh, "Characteristics of acetylated starches prepared using starches separated from different rice cultivars," Journal of Food Engineering, vol. 70, no. 1, pp. 117-127, 2005.

[24] K. Cantor, Blown Film Extrusion. An Introduction, Hanser Publishers, Cincinnati, OH, USA, 2006.
[25] American Society for Testing and Materials, ASTM, Standard D882-10. Standard Test Method for Tensile Properties of Thin Plastic Sheeting, ASTM International, West Conshohocken, Pennsylvania, PA, USA, 2010.

[26] N. Gontard, C. Duchez, J. L. Cuq, and S. Guilbert, "Edible composite films of wheat gluten and lipids: water vapour permeability and other physical properties," International Journal Food Science Technology, vol. 29, no. 1, pp. 39-50, 1994.

[27] American Society for Testing and Materials, ASTM, Standard E96-95. Standard Test Method for Water Vapor Transmission of Materials, ASTM International, West Conshohocken, Pennsylvania, PA, USA, 1995.

[28] D. J. Thomas and W. A. Atwell, Starches: Practical Guides for the Food Industry, Eagan Press Handbook Series AACC, St. Paul, MN, USA, 1999.

[29] V. Guerra-Della, A. Bello-Pérez, R. González-Soto, J. Solorza-Feria, and G. Arambula-Villa, "Efecto del tiempo de reacción en la acetilación de almidón de plátano," Revista Mexicana de Ingeniería Química, vol. 7, no. 3, pp. 283-291, 2008.

[30] J. Huang, H. A. Schols, R. Klaver, Z. Jin, and A. G. J. Voragen, "Acetyl substitution patterns of amylose and amylopectin populations in cowpea starch modified with acetic anhydride and vinyl acetate," Carbohydrate Polymers, vol. 67, no. 4, pp. 542550, 2007.

[31] J. Huang, H. A. Schols, R. Klaver, Z. Jin, and A. G. J. Voragen, "Characterization of differently sized granule fractions of yellow pea, cowpea and chickpea starches after modification with acetic anhydride and vinyl acetate," Carbohydrate Polymers, vol. 67, no. 1, pp. 11-20, 2007.

[32] B. Murua-Pagola, C. I. Beristain-Guevara, and F. MartínezBustos, "Preparation of starch derivatives using reactive extrusion and evaluation of modified starches as shell materials for encapsulation of flavoring agents by spray drying," Journal of Food Engineering, vol. 91, no. 3, pp. 380-386, 2009.

[33] D. L. Phillips, H. Liu, D. Pan, and H. Corke, "General application of Raman spectroscopy for the determination of level of acetylation in modified starches," Cereal Chemistry, vol. 76, no. 3, pp. 439-443, 1999.

[34] R. Rendón-Villalobos, E. García-Hernández, M. GüizadoRodríguez, R. Salgado-Delgado, and N. A. Rangel-Vázquez, "Obtención Y Caracterización De Almidón De Plátano (Musa Paradisiaca L.) Acetilado A Diferentes Grados De Sustitución," Afinidad, vol. 67, no. 548, 2010.

[35] V. C. Solano and R. C. Gante, "Development of biodegradable films based on blue corn flour with potential applications in food packaging. Effects of plasticizers on mechanical, thermal, and microstructural properties of flour films," Journal of Cereal Science, vol. 60, no. 1, pp. 60-66, 2014.

[36] S. Mali, M. V. A. Grossmann, M. García, M. N. Martino, and N. E. Zaritzky, "Mechanical and thermal properties of yam starch films," Food Hydrocolloids, vol. 19, no. 1, pp. 157-164, 2005.

[37] H. Liu, F. Xie, L. Yu, L. Chen, and L. Li, “Thermal processing of starch-based polymers," Process in Polymer Science, vol. 34, no. 12, pp. 1348-1368, 2009.

[38] F. S. Buehler, E. Schmid, and H. J. Schultze, "Starch/polymer mixture, process for the preparation thereof, and products obtainable therefrom," US Patent 5, 346, 936, 1994.

[39] J. Valadez-González, A. Herrera-Franco, P. Herrera-Franco, and F. Zuluaga, "Physicochemical characterization of natural 
and acetylated thermoplastic cassava starch," Dyna, vol. 78, no. 166, pp. 174-182, 2011.

[40] R. L. Shogren, G. F. Fanta, and W. M. Doane, "Development of starch based plastics - a reexamination of selected polymer systems in historical perspective," Starch/Stärke, vol. 45, no. 8, pp. 276-280, 1993.

[41] Q. Yan, H. Hou, P. Guo, and H. Dong, "Effects of extrusion and glycerol content on properties of oxidized and acetylated corn starch-based films," Carbohydrate Polymers, vol. 87, no. 1, pp. 707-712, 2012.

[42] C. A. Gibson and S. P. Nobel, Cactus Primer, First Harvard University Press, 1990.

[43] R. Zullo and S. Iannace, "The effects of different starch sources and plasticizers on film blowing of thermoplastic starch: correlation among process, elongational properties and macromolecular structure," Carbohydrate Polymers, vol. 77, no. 2, pp. 376-383, 2009.

[44] C. D. Arizmendi, Optimización de dos compuestos plastificantes (glicerol y polietilenglicol) en la elaboración de una película plástica comestible obtenida a partir del mucílago de nopal de la especie "Opuntia tomentosa Salm-Dyck". Tesis de Maestría, UAEM, México, 2009.

[45] R. Santana and S. Manrich, "Filmes Tubulares de Compósitos de Termoplásticos Pós-consumo: Análise Térmica e Mecânica," Polímeros, vol. 15, no. 3, pp. 163-170, 2005.

[46] N. Legros, A. Ghaneh-Fard, K. C. Cole, A. Ajji, and M. Dumoulin, "Tensile properties and orientation evolution with processing conditions in polyethylene blown films," Proceedings of ANTEC Society of Plastics Engineers, vol. 1, pp. 169-173, 1998.

[47] Z. González and E. Pérez, "Effect of acetylation on some properties of rice starch," Starch/Stärke, vol. 54, no. 3-4, pp. 148$154,2002$.

[48] S. M. Martelli, G. Moore, S. S. Paes, C. Gandolfo, and J. B. Laurindo, "Influence of plasticizers on the water sorption isotherms and water vapor permeability of chicken feather keratin films," LWT - Food Science and Technology, vol. 39, no. 3, pp. 292-301, 2006.

[49] V. O. López, M. A. García, and N. E. Zaritzky, "Film forming capacity of chemically modified corn starches," Carbohydrate Polymers, vol. 73, no. 4, pp. 573-581, 2008.

[50] T. H. Shellhammer and J. M. Krochta, "Whey protein emulsion film performance as affected by lipid type and amount," Journal of Food Science, vol. 62, no. 2, pp. 390-394, 1997.

[51] H. A. Pushpadass, D. B. Marx, R. L. Wehling, and M. A. Hanna, "Extrusion and characterization of starch films," Cereal Chemistry, vol. 86, no. 1, pp. 44-51, 2009.

[52] A. V. Singh and L. K. Nath, "Synthesis, characterization, and compatibility study of acetylated starch with lamivudine," Journal of Thermal Analysis and Calorimetry, vol. 108, no. 1, pp. 307-313, 2012. 